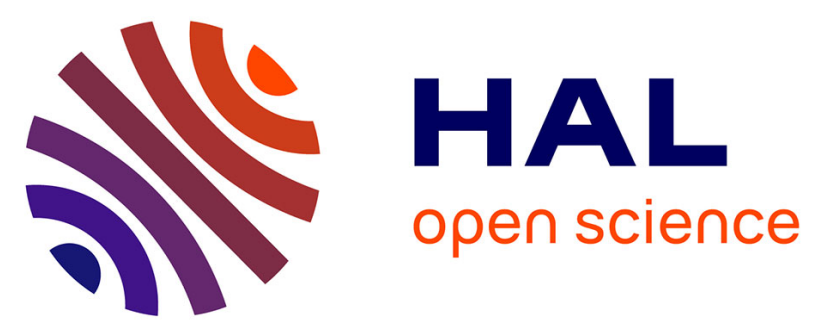

\title{
Second-order optical nonlinearity and ionic conductivity of nanocrystalline GeS2-Ga2S3-LiI glass-ceramics with improved thermo-mechanical properties.
}

Changgui Lin, Laurent Calvez, Bruno Bureau, Haizheng Tao, Mathieu Allix, Zhangxiang Hao, Vincent Seznec, Xianghua Zhang, Xiujian Zhao

\section{To cite this version:}

Changgui Lin, Laurent Calvez, Bruno Bureau, Haizheng Tao, Mathieu Allix, et al.. Second-order optical nonlinearity and ionic conductivity of nanocrystalline GeS2-Ga2S3-LiI glass-ceramics with improved thermo-mechanical properties.. Physical Chemistry Chemical Physics, 2010, 12 (15), pp.3780-7. 10.1039/b921909a . hal-00608320

\section{HAL Id: hal-00608320 https://hal.science/hal-00608320}

Submitted on 23 Aug 2013

HAL is a multi-disciplinary open access archive for the deposit and dissemination of scientific research documents, whether they are published or not. The documents may come from teaching and research institutions in France or abroad, or from public or private research centers.
L'archive ouverte pluridisciplinaire HAL, est destinée au dépôt et à la diffusion de documents scientifiques de niveau recherche, publiés ou non, émanant des établissements d'enseignement et de recherche français ou étrangers, des laboratoires publics ou privés. 


\title{
Second-order optical nonlinearity and ionic conductivity of nanocrystalline $\mathrm{GeS}_{2}-\mathrm{Ga}_{2} \mathrm{~S}_{3}-\mathrm{LiI}$ glass-ceramics with improved thermo-mechanical properties
}

\author{
Changgui Lin, ${ }^{* a b}$ Laurent Calvez, ${ }^{* b}$ Bruno Bureau, ${ }^{b}$ Haizheng Tao, ${ }^{a}$ \\ Mathieu Allix, ${ }^{c}$ Zhangxiang Hao $^{a}{ }^{a}$ Vincent Seznec, ${ }^{d}$ Xianghua Zhang ${ }^{b}$ and \\ Xiujian Zhao*a
}

Received 20th October 2009, Accepted 28th January 2010

First published as an Advance Article on the web 23rd February 2010

DOI: $10.1039 /$ b921909a

\begin{abstract}
IR-transparent chalcogenide glass-ceramics were fabricated through a careful ceramization process of the as-prepared $65 \mathrm{GeS}_{2} \cdot 25 \mathrm{Ga}_{2} \mathrm{~S}_{3} \cdot 10 \mathrm{LiI}$ glasses at a temperature of $403{ }^{\circ} \mathrm{C}$ for various durations. Owing to the precipitation of $\mathrm{Li}_{x} \mathrm{Ga}_{y} \mathrm{~S}_{z}$ crystals with a $\mathrm{Ga}_{2} \mathrm{~S}_{3}$-like structure, clear second-harmonic generation was observed in the sample crystallized at $403{ }^{\circ} \mathrm{C}$ for $60 \mathrm{~h}$, which has a greatly improved resistance to environmental impairment. Additionally, it is found that the shorter crystallization process $(\leqq 60 \mathrm{~h})$ contributed to the enhancement of $\mathrm{Li}^{+}$ionic conductivity, whereas a longer heat-treatment $(80 \mathrm{~h})$ would impair that of the glass-ceramics. The micro-structural origin of these varied properties was elucidated in detail. The corresponding results will be of benefit for the optimization of designed transparent chalcogenide glass-ceramics with improved thermo-mechanical properties, a permanent second-order optical nonlinearity, or a well-enhanced ionic conductivity for application in amorphous solid electrolytes.
\end{abstract}

\section{Introduction}

Chalcogenide glass shows excellent IR transmission ranging from $0.8 \mu \mathrm{m}$ to $10 \mu \mathrm{m}$ (even to $20 \mu \mathrm{m}$ ), thus becoming a valuable building block in IR optics. ${ }^{1}$ In addition to the simplicity of fabrication of complicated optical components, chalcogenide glass with second-order optical nonlinearity (SON) has received a lot of attention because it presents great potential for the conception of electrooptic modulators in IR spectral region. ${ }^{2-4}$ Indeed, an efficient second harmonic generation (SHG) has been observed in chalcogenide glasses after some specific treatments such as optical poling, ${ }^{2}$ thermal/electric poling, ${ }^{3}$ and electron beam irradiation. ${ }^{4}$ However, the advantages of the worked glasses are largely restricted by their relatively weak thermo-mechanical properties and unstable SHG which is declining with time due to structural relaxation. ${ }^{5}$ Fortunately, glass-ceramics with crystal phases of an asymmetric center shows another route for the permanent SHG and enhanced mechanical properties, meanwhile keeping the usual advantage of fabrication versatility. ${ }^{6}$ Furthermore, electron-phonon interactions, which have been shown in the photoinduced SHG studies, would also possibly contribute to the resultant nonlinear optical susceptibilities of such composites. ${ }^{7}$

${ }^{a}$ Key Laboratory of Silicate Materials Science and Engineering (Wuhan University of Technology), Ministry of Education, Wuhan, Hubei 430070, PR China. E-mail: linchanggui@gmail.com, opluse@whut.edu.cn

${ }^{b}$ Laboratoire des Verres et Céramiques, UMR-CNRS 6226, Sciences chimiques de Rennes, Université de Rennes 1, 35042 Rennes Cedex, France. E-mail: laurent.calvez@univ-rennes1.fr CNRS, UPR3079 CEMHTI, 45071 Orléans Cedex 2, France

${ }^{d}$ Laboratoire de Réactivité et Chimie des Solides, UMR CNRS 6007, Université de Picardie Jules Verne, 33 rue St. Leu,

80039 Amiens Cedex, France
Since the first investigation on crystallization of chalcogenide glasses for improving their mechanical properties reported by Melchosky et al., ${ }^{8}$ numerous crystallization experiments have been performed to obtain transparent glass-ceramics through the precipitation of nano-crystals. Even so, it is still difficult to achieve a controlled crystallization for a desired microstructure with designed-in, highly specialized properties. Recent results indicated that some glass components, e.g. alkali halide, could be added to affect crystallization behavior by self-nucleating, and nucleating agent was also used to promote phase separation and internal nucleation. ${ }^{9}$ Subsequently, reproducible IR-transmitting glass-ceramics with enhanced thermo-mechanical properties were successfully fabricated through a careful crystallization process. ${ }^{9}$ In the long list of various chalcogenide glasses, $\mathrm{GeS}_{2}-\mathrm{Ga}_{2} \mathrm{~S}_{3}$ based glasses have created interest recently because of their potential host for rare-earth ions, nontoxicity and more preferable physicochemical properties compared to As-based or other base sulfides. ${ }^{10,11}$ Gallium plays an electron efficient role, forming a dative bond with the lone pair electrons of $\mathrm{S}$ atom, producing the shortest cutoff edge at a shorter wavelength than the usual As-, Sb-, and In-based glasses. ${ }^{9,12}$ Furthermore, based on the previous literature, ${ }^{10,13}$ it also can be expected that the glass former of gallium would act as a self-nucleating agent during heattreatments to uniformly precipitate many non-centrosymmetirc nanocrystals suitable for permanent SHG.

In this study, LiI was introduced to increase the glassforming ability of $\mathrm{GeS}_{2}-\mathrm{Ga}_{2} \mathrm{~S}_{3}$ based glasses, and also to facilitate a controllable nucleation and crystal growth for the fabrication of transparent glass-ceramics. Moreover, a newly developed and SON crystal of $\mathrm{LiGaS}_{2}{ }^{14}$ would also be expected to be precipitated by ceramization of the said chalcogenide 
glass. As discussed above, the $\mathrm{GeS}_{2}-\mathrm{Ga}_{2} \mathrm{~S}_{3}$ based glasses have been studied extensively for many optical applications such as optical amplifier, solid-state lasers, and optical modulator. However, very few works have focused on the fast ionic conductivity of these base glasses containing Li despite the fact that higher ionic conductivity and better thermal stability (high glass transition temperature, $T_{\mathrm{g}}$ ) would be achieved simultaneously. ${ }^{15}$ Li-containing sulfide glasses show higher ionic conductivity than oxide glasses, and as amorphous solid electrolytes, possess a far greater degree of freedom in material design than the crystalline ones. ${ }^{15}$ Although the ionic conductivity of glassy materials is generally higher than that of corresponding crystalline ones due to their so-called open structure ${ }^{16}$ it has been revealed that partial crystallization leads to an enhancement of the ionic conductivity in oxide glass-ceramics. ${ }^{17}$ Nevertheless, no such study of ionic conductivity in chalcogenide glass-ceramics was ever reported. Consequently, it is of great interest and important to clarify crystallization behavior, mechanical, optical properties, and ionic conductivity for the technical applications of such transparent nanocrystalline glass-ceramics. Hereinafter, IR-transmitting glass-ceramics with SON properties was successfully fabricated from the ceramization of base glass with a composition of $65 \mathrm{GeS}_{2} \cdot 25 \mathrm{Ga}_{2} \mathrm{~S}_{3} \cdot 10 \mathrm{LiI}$ (GGL-10), which has good chemical durability and is suitable for a controllable crystallization. ${ }^{9}$ The ionic conductivity and enhanced mechanical properties of the crystallized samples were investigated in detail, and their features related to nanocrystalline microstructure will be firstly elucidated by X-ray diffraction (XRD), scanning electronic microscopy (SEM), and solid state NMR.

\section{Experimental}

GGL-10 bulk glass was prepared by melting the high pure raw materials $(\mathrm{Ge}, \mathrm{Ga}$, and $\mathrm{S}$ of $5 \mathrm{~N}$, LiI of $3 \mathrm{~N})$ under vacuum $\left(10^{-3} \mathrm{~Pa}\right)$ in a sealed silica ampoule. The details of glass preparation can be found elsewhere. ${ }^{10}$ The characteristic temperatures of the as-prepared glass were determined by differential scanning calorimeter (DSC, Type: DSC Q20 Thermal Analysis). Hermetic aluminium pans with $\sim 10 \mathrm{mg}$ samples were heated from room temperature until crystallization completed under a $\mathrm{N}_{2}$ atmosphere in the DSC machine. The glass transition temperature $T_{\mathrm{g}}$, on-set crystallization temperature $T_{\mathrm{x}}$, and crystallization peak temperature $T_{\mathrm{p}}$ were obtained using the microprocessor of thermal analyzer with an accuracy of $1{ }^{\circ} \mathrm{C}$. Based on the DSC results, the crystallization process was conducted by heating at a rate of $2{ }^{\circ} \mathrm{C} \mathrm{min}^{-1}$ to a specified temperature, $T_{\mathrm{HT}}$ (above $T_{\mathrm{g}}$ ), preserving for various durations, and then cooling slowly to room temperature.

The crystalline phases present in the heat-treated samples were identified using a Bruker-AXS D8 (Karlsruhe, Germany) Advanced diffractometer with a conventional $\theta-\theta$ BraggBrentano configuration, and confirmed reciprocally by the ${ }^{7} \mathrm{Li}$ and ${ }^{71} \mathrm{Ga}$ NMR experiments. ${ }^{18}$ The ${ }^{7} \mathrm{Li}$ spectra were recorded at room temperature on an Avance 300 Bruker spectrometer operating at $39 \mathrm{MHz}$ with a $4 \mathrm{~mm}$ magic angle spinning (MAS) probe spinning at $10 \mathrm{kHz}$. And the ${ }^{71} \mathrm{Ga}$ (spin $I=3 / 2$ ) spectra were recorded at $91.5 \mathrm{MHz}$ with a static probe. The decomposition of the experimental spectra was performed using the Dmfit\#20080317 Version of the Dmfit software. ${ }^{19}$

The size or morphology of crystallites was observed by SEM with the technique described elsewhere, ${ }^{9}$ in a fresh scratch created on sample surface. Samples for transmission electron microscopy (TEM) were prepared by crushing the samples in ethanol. The small crystallites in the suspension were deposited onto a holey carbon film, supported by a copper grid. Imaging (bright field and dark field) studies were carried out with a Philips (Eindhoven, the Netherlands) CM20 electron microscope operating at $200 \mathrm{kV}$. The transmission spectra of the as-prepared and heat-treated samples were recorded with a CARY5 double-beam spectrophotometer (Varian, Mulgrave, Vic., Australia) in the visible and near-IR (Vis-NIR) spectral region. The second harmonic (SH) intensity of the glass-ceramics was measured at room temperature using Maker fringe technique. The source was a Q-switched $\mathrm{Nd}$ :YAG laser operating at $1064 \mathrm{~nm}$ fundamental wavelength with pulse of $10 \mathrm{~ns}$ ( $30 \mu \mathrm{J}$ per pulse). The beam area is about $1 \mathrm{~mm}$ in diameter, and no damage of samples was observed after experiments. Y-cut $\alpha$-quartz with a thickness of $1.11 \mathrm{~mm}$ was used as a reference. Combination of $\mathrm{p}$ excitation and $\mathrm{p}$ detection was used during the SHG measurements. Conductivities were measured under argon by the complex impedance method using a HP4192A frequency analyzer at temperatures ranging from room temperature to $250{ }^{\circ} \mathrm{C}$.

To learn if the thermo-mechanical properties improved after crystallization, thermal expansion coefficient (TEC) $\alpha$, Vickers hardness, fracture toughness, and Young's modulus, etc. were measured in the as-prepared and crystallized samples. TEC was determined using a TMA 2940 Calorimeter (TA Instruments) at a heating rate of $2{ }^{\circ} \mathrm{C} \mathrm{min}^{-1}$ from room temperature to $200{ }^{\circ} \mathrm{C}$ with an error of $2 \times 10^{-7} \mathrm{~K}^{-1}$. Vickers microindenter (Matsuzawa VMT-7S, Matsuzawa Co. Ltd., Tokyo, Japan) was used to obtain the hardness with a charge of $100 \mathrm{~g}$ for $5 \mathrm{~s}$. All the characteristics were averaged over measurements on 10 indentations per sample with an error of $2 \mathrm{~kg} \mathrm{~mm}^{-2}$. Fracture toughness $\left(K_{\mathrm{c}}\right)$ was then calculated by the modified Palamqvist's method ${ }^{20}$ using the following equation:

$$
K_{\mathrm{c}}=0.016\left(\frac{E}{H}\right)^{1 / 2} \frac{P}{c^{3 / 2}}
$$

where $H$ is Meyer's hardness $\left(H=P / 2 a^{2}\right), P$ (in newtons) is the load applied on the indenter, $c(\mathrm{~m})$ is half the mean length of the two radical cracks (tip to tip), and $E$ (GPa) is Young's modulus, obtained by measuring ultrasound propagation speed in the samples. Density, $\rho$, was measured using the Archimedes technique which consists in comparing the difference of sample weight in the air and in a solvent. A Metler Toledo XS64 balance was used with distilled water as a solvent.

\section{Results}

\section{Crystallization behavior}

Since crystallization of chalcogenide glass is a highly exothermic process, DSC is a very suitable technique for a reasonable description of crystallization process. The characteristic 
temperatures $\left(T_{\mathrm{g}}, T_{\mathrm{x}}\right.$, and $\left.T_{\mathrm{p}}\right)$ of GGL-10 glass can be obtained from a typical DSC curve as shown in Fig. 1. DSC curves may contain more exothermic peaks (see Fig. 1), but only the lowest temperature peak is worthwhile to be considered in discussing glass stability. The $\Delta T\left(T_{\mathrm{x} 1}-T_{\mathrm{g}}\right)$ value is an indication of the devitrification tendency of a glass when heated above $T_{\mathrm{g}}$. The larger $\Delta T$ indicates good glass stability, whereas the lower $\Delta T$ indicates that it is not easy to control its crystallization process. In this case, a suitable $\Delta T$ value of $\sim 100{ }^{\circ} \mathrm{C}$ indicates it a sub-stable glass, which is appropriate for controllable process of nucleation and crystal growth. ${ }^{21}$ So far the crystallization behavior of the studied glass can be roughly described by the above parameters, but more detailed investigation is needed to control the crystallization.

An insight of crystallization behavior of the crystalline phases, which are responsible for the two distinct exothermic peaks in Fig. 1, is necessary for fabricating glass-ceramics with designed-in, highly specialized properties. As shown in Fig. 2(a), the DSC curves of crystallized GGL-10 samples provide the information of transformation of crystalline phases. The first (low-temperature) crystallization peak (CP) obviously decreases with the elongation of annealing durations, and vanishes after $60 \mathrm{~h}$ heat-treatment indicating the full crystallization of the associated crystal phase. The inset of Fig. 2(b) shows the integral area of the second CP for GGL-10 base glass. Assuming the area of DSC peak would be proportional to the volume of the glass remaining after a heat-treatment, ${ }^{22}$ as indicated in Fig. 2(b), it can be concluded that the crystalline phase related to the second CP is hardly precipitated during the $80 \mathrm{~h}$ heat-treatments. Subsequently, a remarkable decrease of the second $\mathrm{CP}$ is observed in glassy sample after a longer heat-treatment of $100 \mathrm{~h}$, suggesting the precipitation of the crystalline phase related to the second $\mathrm{CP}$.

According to the indication from the above results, a fairly low $T_{\mathrm{HT}}$ of $403{ }^{\circ} \mathrm{C}\left(T_{\mathrm{g}}\right)$ was selected for crystallization process. Subsequently, a set of crystallized samples with a thickness of $\sim 1.2 \mathrm{~mm}$ were obtained via placing the base glasses in a ventilated furnace at $403{ }^{\circ} \mathrm{C}$ for various durations. The obtained glass-ceramics are bulk crystallization and optical homogeneity to the naked eye as shown in Fig. 3. To clearly elucidate the structural evolution of the obtained glass-ceramics, some effective techniques such as SEM, XRD, and NMR,

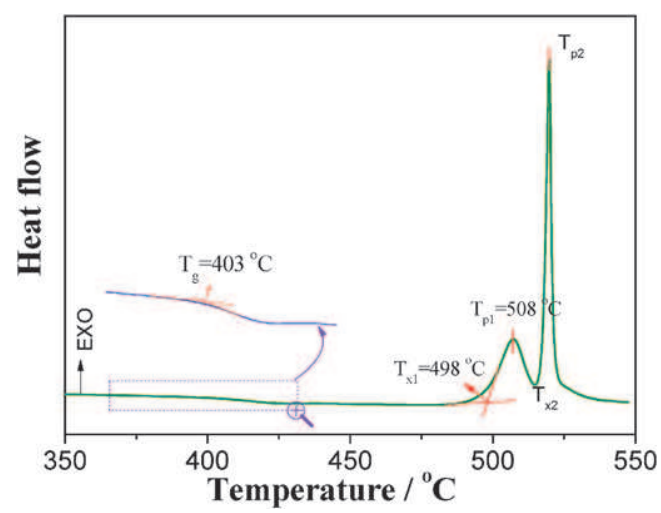

Fig. 1 DSC curve for bulk glass of GGL-10 at a heating rate of $10{ }^{\circ} \mathrm{C} \mathrm{min}{ }^{-1}$. The definition of characteristic temperatures has been schematically indicated.
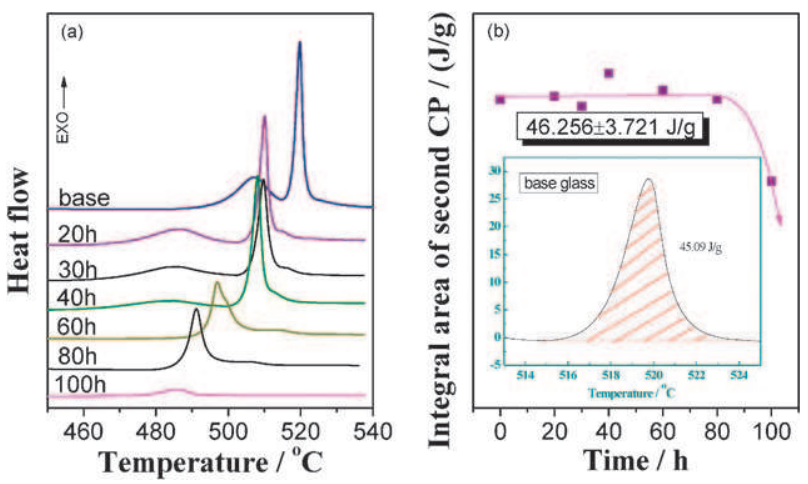

Fig. 2 (a) DSC curves of the GGL-10 glass heat-treated at $403{ }^{\circ} \mathrm{C}$ for different durations (DSC heating rate of $15{ }^{\circ} \mathrm{C} \mathrm{min}{ }^{-1}$ ). (b) Integral area of the second $\mathrm{CP}$ of the heat-treated glasses $v$ s. heat-treated durations. The inset of (b) is the integral area of the second $\mathrm{CP}$ for GGL-10 base glass.

were employed for providing the direct evidence of structural transformation. As shown in Fig. 4, the morphologies of crystallites were observed on those samples that were heat treated at $403{ }^{\circ} \mathrm{C}$ for $20 \mathrm{~h}, 30 \mathrm{~h}, 40 \mathrm{~h}$, and $60 \mathrm{~h}$, respectively. The inset of Fig. 4(a) indicates that the crystallites with a size of $\sim 20 \mathrm{~nm}$ are responsible for the slight decrease of transmittance in the glass sample after $20 \mathrm{~h}$ heat-treatment (the biggest particles are around $40 \mathrm{~nm}$ and the smallest of $\sim 15 \mathrm{~nm}$ ). When the heat-treated time was extended from $20 \mathrm{~h}$ to $60 \mathrm{~h}$, the size and amount of nano-particles increased simultaneously. As indicated in Fig. 4d), most impressively, the degree of crystallinity exceeds about $60 \%$ in the glass heat treated for $60 \mathrm{~h}$ which still remains an excellent transmission in the IR spectral region. To identify the crystalline phases, XRD patterns of the crystallized glasses are shown in Fig. 5, in which the bulk samples were used. At the first sight, all diffraction peaks of the obtained glass-ceramics in Fig. 5 are very similar to that of $\mathrm{Ga}_{2} \mathrm{~S}_{3}$ crystalline reference. However, it is very important to note that a slight dissimilarity is observable for their diffraction peaks compared to that of $\mathrm{Ga}_{2} \mathrm{~S}_{3}$ crystal, and similar to the difference between that of $\mathrm{Ga}_{2} \mathrm{~S}_{3}$ and $\mathrm{Ga}_{1.96} \mathrm{Li}_{0.12} \mathrm{~S}_{3}$ as displayed by the curves $\mathrm{a}$ and $\mathrm{b}$ in Fig. 5. Consequently, it is reasonable to speculate that $\mathrm{Li}$ is involved in the crystallization to precipitate the $\mathrm{Ga}_{2} \mathrm{~S}_{3}$-like crystallites of $\mathrm{Li}_{x} \mathrm{Ga}_{y} \mathrm{~S}_{z}$.

To clarify the behavior of $\mathrm{Li}$ and $\mathrm{Ga}$ atoms during the crystallization, solid state NMR technique is used in the GGL-10 glass-ceramics and some commercial crystalline references, such as $\mathrm{Li}_{2} \mathrm{~S}$ and LiI. ${ }^{71} \mathrm{Ga}$ NMR spectra of the obtained glass-ceramics recorded in static mode are presented with the variation of heat-treated times in Fig. 6. To begin with, a broad profile is observed in the base glass, which is attributed to the amorphous phase. With elongation of heattreatments, subsequently, sharp peaks ascribed to crystalline state arise gradually from the broad base profile. The progressive acumination of these peaks originates from the precipitation of crystalline phase containing gallium. Combined with the XRD results, therefore, we can suppose that $\mathrm{Ga}_{2} \mathrm{~S}_{3}$-like crystal phase is separated from the GGL-10 glass matrix during the crystallization process. Furthermore, the behavior of lithium during the heat-treatment is revealed by 


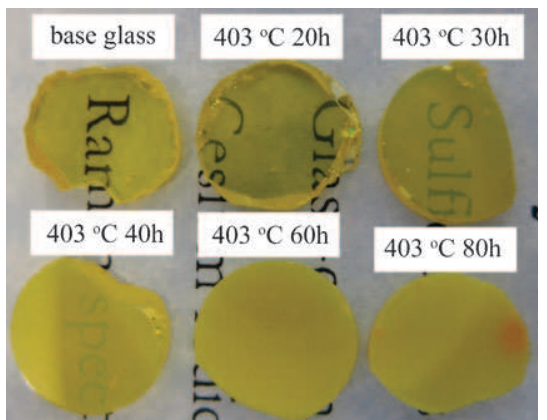

Fig. 3 Photograph of the GGL-10 samples crystallized at $403{ }^{\circ} \mathrm{C}$ for different durations.

the ${ }^{7} \mathrm{Li}$ NMR spectra as shown in Fig. 7. It is a distinct evidence that a new peak located at $\sim 0.4 \mathrm{ppm}$ of chemical shift was appeared with the precipitation of $\mathrm{Ga}_{2} \mathrm{~S}_{3}$-like crystal phase, further indicating the lithium is incorporated into the crystalline ones. It is also seen that the main chemical shifts measured for base glass are about -1.8 and $-2.4 \mathrm{ppm}$, which is between that of $\mathrm{LiI}$ and $\mathrm{Li}_{2} \mathrm{~S}$ references. Therefore, it can be assumed that the Li atoms in the GGL-10 base glass locate at a mixed environment consisted of sulfide and iodide anions. Another point worthy noting is that these two peaks located at -1.8 and $-2.4 \mathrm{ppm}$ sharpen with the progress of crystallization, indicating that the glass matrix surrounding $\mathrm{Li}$ is rearranged less erratically. In addition, the new peak of $\sim 0.4 \mathrm{ppm}$ is located quite near to that of $\mathrm{Li}_{2} \mathrm{~S}$ reference after the crystallization process, suggesting the surroundings of the $\mathrm{Li}$ atoms in the precipitated crystallites is mostly $\mathrm{S}^{2-}$. Consequently, we confirmed again that the resultant crystal is $\mathrm{Li}_{x} \mathrm{Ga}_{y} \mathrm{~S}_{z}$ with a $\mathrm{Ga}_{2} \mathrm{~S}_{3}$-like structure. In other words, it is believed that the $\mathrm{Li}$ atoms penetrate into the crystallites of $\mathrm{Ga}_{2} \mathrm{~S}_{3}$ during heat-treatment. Another extremely important

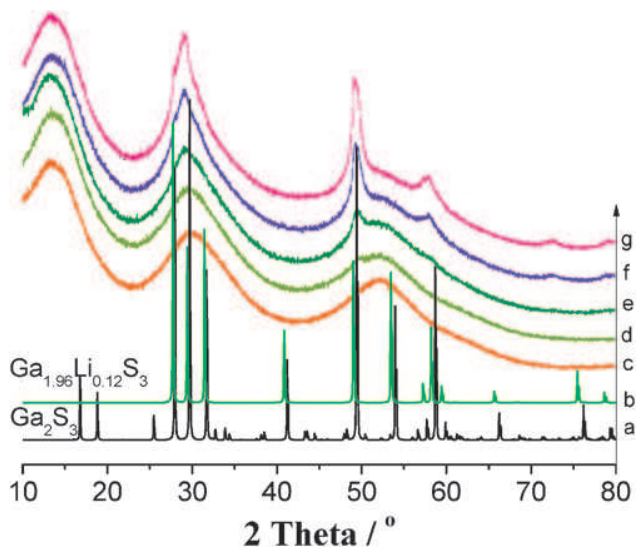

Fig. 5 XRD patterns of JCPDF cards of No. 84-1440 (a, $\left.\mathrm{Ga}_{2} \mathrm{~S}_{3}\right)$ and No. 37-883 (b, $\mathrm{Ga}_{1.96} \mathrm{Li}_{0.12} \mathrm{~S}_{3}$ ), and GGL-10 glasses crystallized at $403{ }^{\circ} \mathrm{C}$ for (c) $0 \mathrm{~h}$ (base glass), (d) $30 \mathrm{~h}$, (e) $40 \mathrm{~h}$, (f) $60 \mathrm{~h}$, and (g) $80 \mathrm{~h}$, respectively.

phenomenon is that the intensity of the newly emerged peak $(0.4 \mathrm{ppm})$ increases with the elongation of heat-treated times, reaches a maximum after the $60 \mathrm{~h}$ heat-treatment, and then decreases gradually when the annealing time exceeds $80 \mathrm{~h}$. It suggests that the Li atoms take part in the crystallization at the first $60 \mathrm{~h}$ heat-treatment, and reach a saturation point in the sample crystallized for $60 \mathrm{~h}$. Thereafter, the high-temperature atmosphere $\left(403{ }^{\circ} \mathrm{C}\right)$ drives them to move out from the precipitated crystallites or prefer to crystallize other more stable crystal phase related to the second CP in the DSC curves. In addition, as shown in Fig. 8, it is manifest that the decrease of second CP in the sample crystallized for $100 \mathrm{~h}$ (in Fig. 2) is originated from the precipitation of $\mathrm{Li}_{4} \mathrm{GeS}_{4}$ or $\mathrm{GeS}_{2}$ crystals. Thus, it can be concluded that subsequent to the completion of crystallization of the first crystalline phase
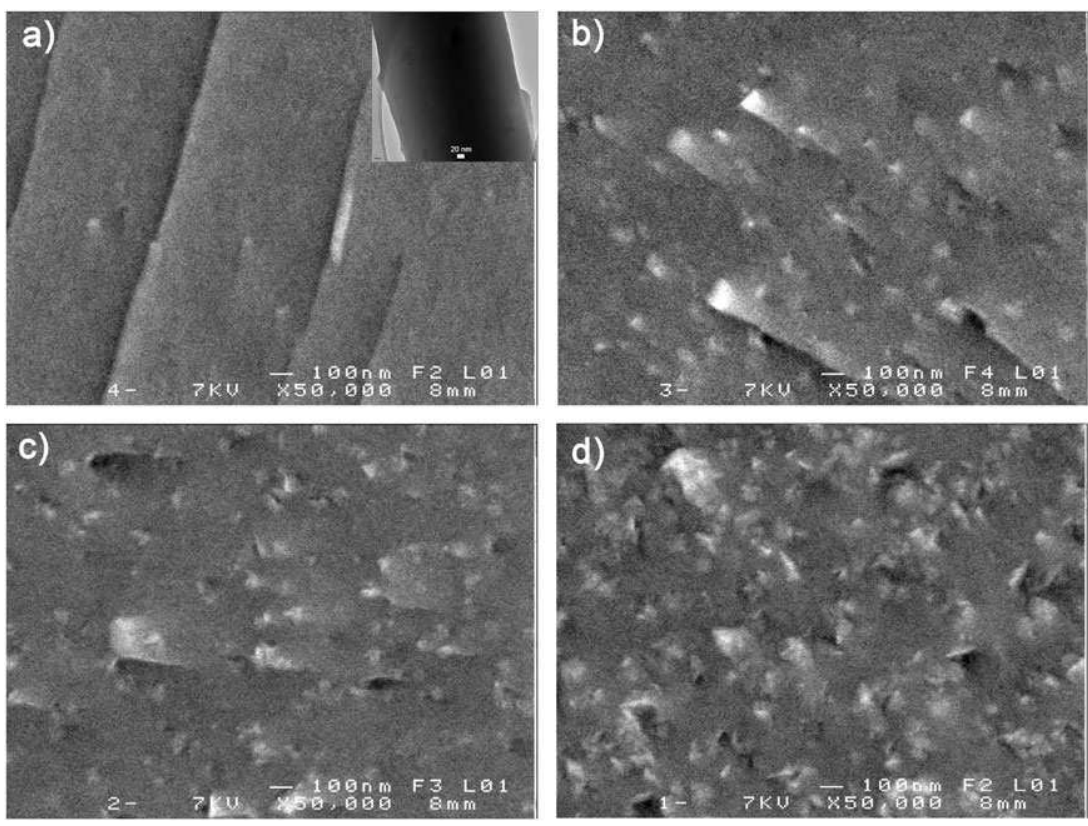

Fig. 4 SEM images for GGL-10 samples crystallized at $403{ }^{\circ} \mathrm{C}$ for different durations: (a) $20 \mathrm{~h}$, (b) $30 \mathrm{~h}$, (c) $40 \mathrm{~h}$, and (d) $60 \mathrm{~h}$, respectively. The inset of (a) is the TEM image of GGL-10 glass after $20 \mathrm{~h}$ heat-treatment. 


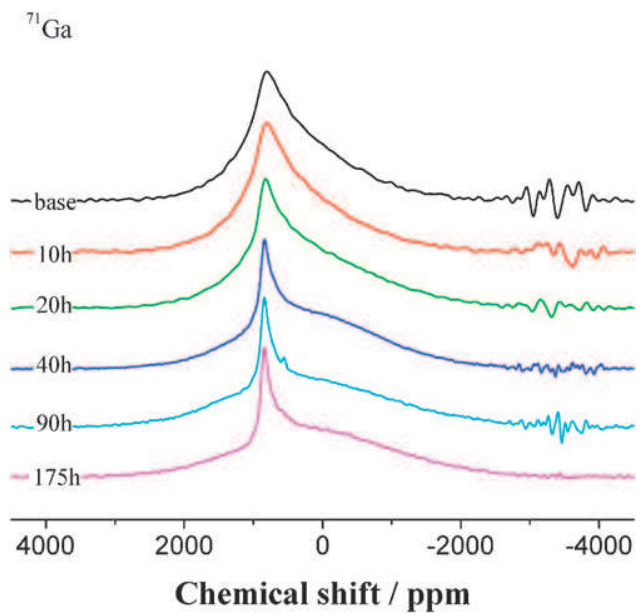

Fig. $6{ }^{71}$ Ga NMR spectra of GGL-10 samples crystallized for different durations (from 0 to $175 \mathrm{~h}$ ).

$\left(\mathrm{Li}_{x} \mathrm{Ga}_{y} \mathrm{~S}_{z}\right.$ ), the second phase of $\mathrm{GeS}_{2}$-related crystal begins to separate out, which also might be penetrated into by Li atoms.

\section{Physical and thermo-mechanical properties}

Some physical and thermo-mechanical properties of the obtained samples were studied in detail, and the results were listed in Table 1. It is observable that the strength of this IR glass is strongly reinforced after crystallization process. Impressively, $\sim 8 \%$ enhancement is for the hardness, $45 \%$ increase for fracture toughness, and $22 \%$ decrease for TEC, respectively. More importantly, good transparency still remains in the IR spectral region as shown in Fig. 9. The maximum transmittance keeps almost the same and only begins to decrease after a quite long heat-treatment of $80 \mathrm{~h}$. The precipitation of the main glass former $\left(\mathrm{GeS}_{2}\right.$-related crystallites) should take the primary responsibility for the transmission decrease in the sample crystallized for $80 \mathrm{~h}$. We would like to point out that the GGL-10 glass crystallized for

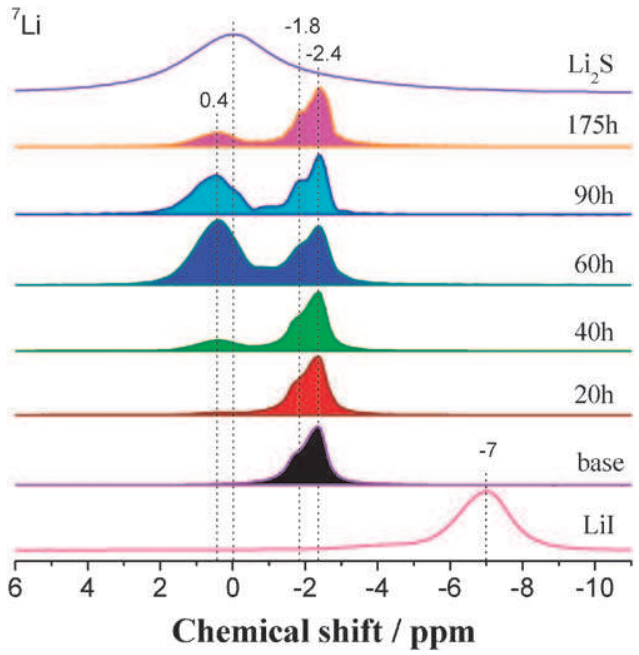

Fig. $7 \quad{ }^{7}$ Li NMR spectra of GGL-10 samples crystallized for different durations (from 0 to $175 \mathrm{~h}$ ). NMR spectra of crystalline LiI and $\mathrm{Li}_{2} \mathrm{~S}$ (used as a reference) are also presented, respectively. The lines are guide to the eye.

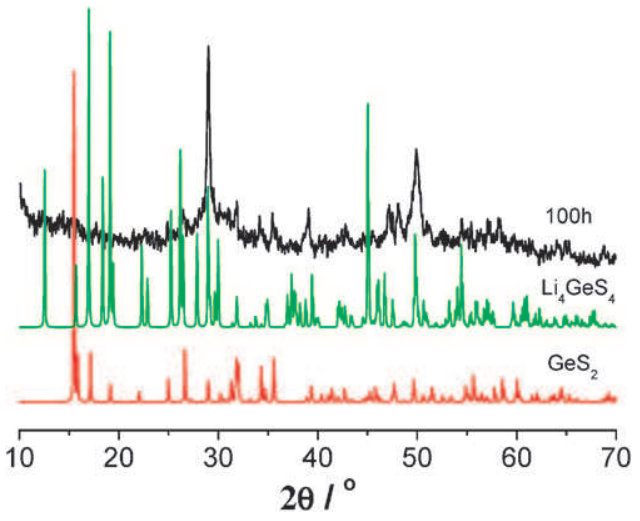

Fig. 8 XRD patterns of JCPDF cards of No. 89-4330 $\left(\mathrm{Li}_{4} \mathrm{GeS}_{4}\right)$ and No. 75-1978 $\left(\mathrm{GeS}_{2}\right)$, and GGL-10 samples crystallized at $403{ }^{\circ} \mathrm{C}$ for $100 \mathrm{~h}$, respectively.

$60 \mathrm{~h}$ has preferably good mechanical properties and a really low TEC, meanwhile keeps an excellent IR transmittance. To the best of our knowledge, it is the lowest TEC obtained in chalcohalide glasses. ${ }^{21,23}$

\section{SON and ionic conducting properties}

As represented above, it can be looked forward that this IR-transparent glass-ceramics with a well enhanced resistance to environmental impairment would offer promise for many potential new applications. A cheap and efficient optical converter will be one of the potential applications for the studied glass-ceramics with a permanent SON property, especially added to the random quasi-phase-matching technique. ${ }^{24}$ Using the typical Maker fringe technique, SHG was observed in the IR-transparent glass-ceramics of $60 \mathrm{~h}$ heat-treatment as shown in Fig. 10. The intensity of SH signal shows a strong dependence on the rotational angle of samples, and reaches a maximum when the incident angle is near $0^{\circ}$. A maximum $\mathrm{SH}$ intensity approximately of $3.5 \times 10^{-3}$ compared with that of the reference (Y-cut $\alpha$-quartz single crystal) was obtained in the glass annealed at $403{ }^{\circ} \mathrm{C}$ for $60 \mathrm{~h}$, which has the best mechanical and thermal properties and meanwhile remains the advantage of the good IR-transmittance. Alternatively, for other potential applications of solid state electrolytes it would

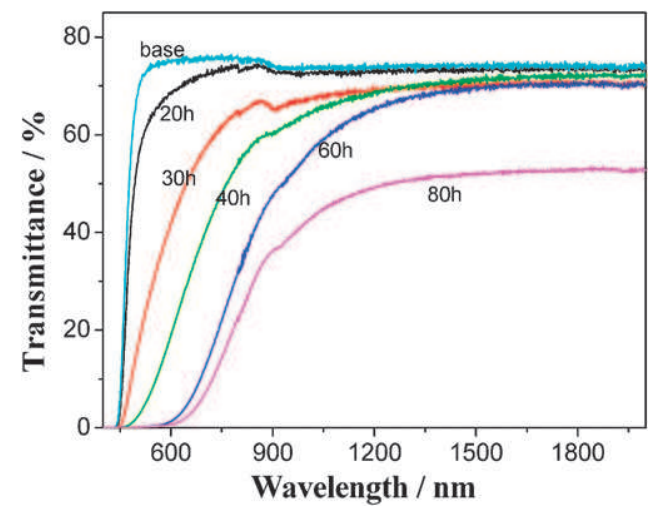

Fig. 9 Transmission spectra of the GGL-10 samples in Vis-NIR region: base glass and samples crystallized at $403{ }^{\circ} \mathrm{C}$ for different durations. 
Table 1 Some physical and thermo-mechanical properties of the studied samples

\begin{tabular}{llllll}
\hline Samples & $\begin{array}{l}\text { Cut-off edge } \\
\text { (half of trans.) }( \pm 1 \mathrm{~nm})\end{array}$ & $\begin{array}{l}\text { Density, } \rho \\
\left( \pm 0.002 \mathrm{~g} \mathrm{~cm}^{-3}\right)\end{array}$ & $\begin{array}{l}\text { Hardness, } H_{\mathrm{v}} \\
\left( \pm 2 \mathrm{Kg} \mathrm{mm}^{-2}\right)\end{array}$ & $\begin{array}{l}\text { Fracture toughness, } \\
K_{\mathrm{c}}\left( \pm 0.005 \mathrm{MPa} \mathrm{m}^{-1 / 2}\right)\end{array}$ & $\begin{array}{l}\text { TEC, } \alpha \\
\left( \pm 1 \times 10^{-7} \mathrm{~K}^{-1}\right)\end{array}$ \\
\hline Base & 468 & 3.036 & 212.7 & 0.199 & 127 \\
$20 \mathrm{~h}$ & 477 & 3.039 & 223.0 & 0.193 & 124 \\
$30 \mathrm{~h}$ & 569 & - & 224.7 & 0.203 & 112 \\
$40 \mathrm{~h}$ & 677 & - & 228.6 & 0.222 & 128 \\
$60 \mathrm{~h}$ & 819 & 3.073 & 229.7 & 0.258 & 98 \\
$80 \mathrm{~h}$ & 832 & - & 230.5 & 0.289 & 102 \\
\hline
\end{tabular}

also be worthwhile to devote much effort on the studied sulfide glasses, which are more easily fabricated into complex shapes by molding and have wide compositional flexibility to optimize their properties and conductivity. Fig. 11 shows the logarithmic plots of conductivity of GGL-10 base glass and glass-ceramics as a function of temperature. It is obvious that starting from the GGL-10 base glass, the $\mathrm{Li}^{+}$ionic conductivity of GGL-10 glass-ceramics increases at the initial crystallization of $40 \mathrm{~h}$ heat-treatment, and then decreases strongly after a long heattreatment of $80 \mathrm{~h}$. It is the first investigation of the evolution of $\mathrm{Li}^{+}$ionic conductivity in chalcogenide glass-ceramics, although similar effects already have been observed in some oxide glass-ceramics. ${ }^{16}$

\section{Discussion}

The crystallization of glasses is too complicated to achieve a full and exact description. Partial facts can be revealed by using some advanced techniques, such DSC, XRD, and NMR. In our previous study, ${ }^{10}$ crystallization behavior in $80 \mathrm{GeS}_{2}$. $20 \mathrm{Ga}_{2} \mathrm{~S}_{3}$ is investigated in detail. The results indicate that for the two CPs in DSC curve, the first CP is attributed to the formation of $\mathrm{Ga}_{2} \mathrm{~S}_{3}$ crystallites, while the other one originates from the precipitation of $\mathrm{GeS}_{2}$ crystallites. Similarly, in GGL-10 glass, the DSC curves of crystallized samples also provide the information on the transformation of crystalline phases, as

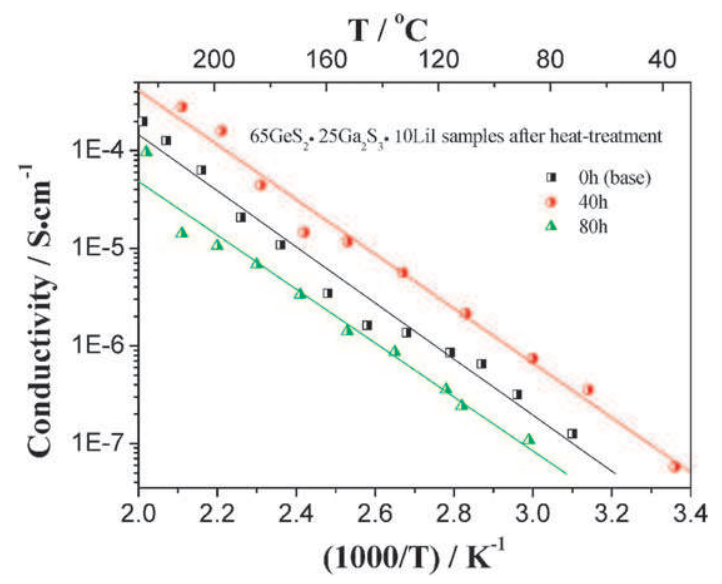

Fig. 11 Temperature dependence of conductivity for the GGL-10 base glass and samples after $40 \mathrm{~h}$ and $80 \mathrm{~h}$ heat-treatments.

shown in Fig. 2. According to the XRD and NMR results, the precipitation of $\mathrm{Li}_{x} \mathrm{Ga}_{y} \mathrm{~S}_{z}$ crystals with a $\mathrm{Ga}_{2} \mathrm{~S}_{3}$-like structure is responsible for the exotherm of the first $\mathrm{CP}$, and completes after the $60 \mathrm{~h}$ heat-treatment. The decrease of second CP in the glass crystallized for $100 \mathrm{~h}$ is originated from the precipitation of $\mathrm{Li}_{4} \mathrm{GeS}_{4}$ or $\mathrm{GeS}_{2}$ crystals. In the other words, it is sure that the $\mathrm{Li}_{x} \mathrm{Ga}_{y} \mathrm{~S}_{z}$ crystallites are precipitated after the initial crystallization process ( $\leqq 60 \mathrm{~h}$ ) in GGL-10 glass, which will be valuable for fabricating a glass-ceramics with specific

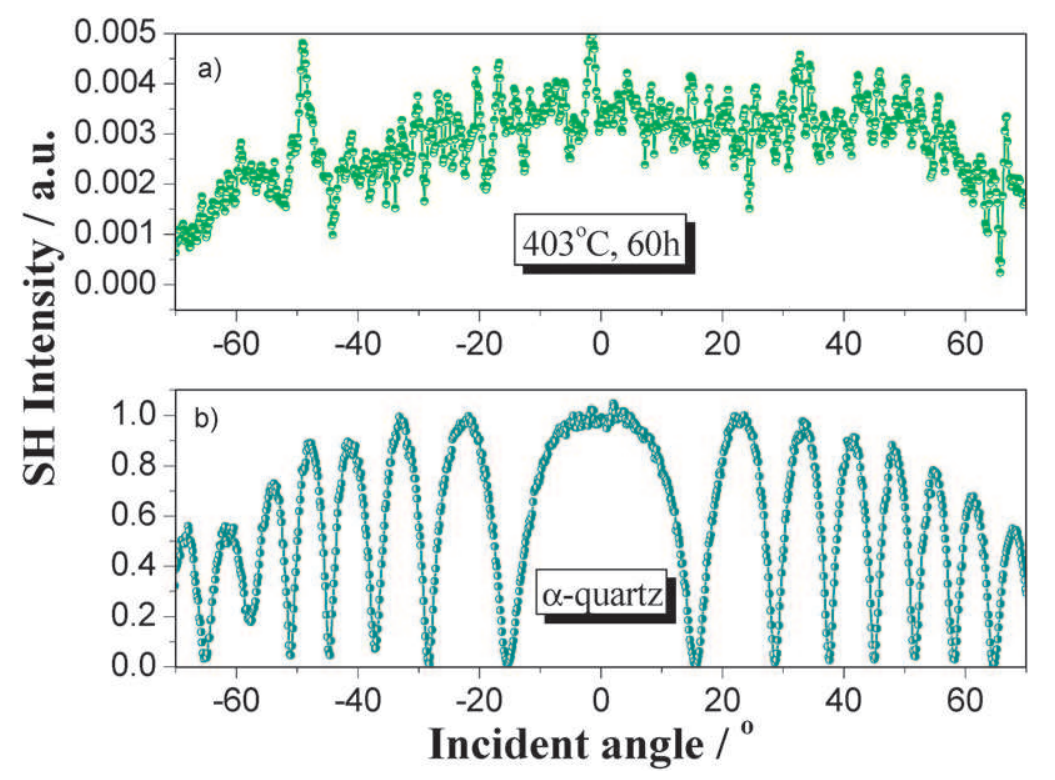

Fig. 10 Maker fringe patterns of (a) GGL-10 glass crystallized at $403{ }^{\circ} \mathrm{C}$ for $60 \mathrm{~h}$, and (b) reference of Y-cut $\alpha$-quartz, respectively. The maximum of $\mathrm{SH}$ intensity for the reference is set to 1 . Other samples have the same $\mathrm{SH}$ profiles with different intensities. 
properties. And by controlling the annealing time, the precipitation of main glass-former can be inhibited to obtain transparent glass-ceramics. In addition, to control the phase separation process, it is essential that heat-treatment takes place in a temperature range where the crystallization rate is very low. In this study, it is evident in Fig. 4 that the particles grow slowly from the size of $20 \mathrm{~nm}$ to $100 \mathrm{~nm}$, meanwhile the nucleation also takes place so as to achieve nearly $60 \%$ crystallinity degree. It is an exact case that the heat-treated temperature of $403{ }^{\circ} \mathrm{C}$ is among the overlap of nucleation and crystal-growth rate curves. This controllable nucleation and crystal-growth is also the key point to get the nanocrystalline glass-ceramics with good transparency.

One can see a progressive strengthening of the glasses by generating nano-crystals inside the glassy matrix. Different from previous chalcohalide glass-ceramics, ${ }^{9,25}$ it is the first one presenting a simultaneous enhancement of hardness and fracture toughness. The precipitation of crystals conducing to more compact composites in GGL-10 glass, demonstrated by an increasing density as shown in Table 1 . Moreover, the transformation of network modifier $\mathrm{Li}^{+}$and $\left[\mathrm{S}_{3} \mathrm{Ga}-\mathrm{GaS}_{3}\right]$ ethane-like units to $\mathrm{Li}_{x} \mathrm{Ga}_{y} \mathrm{~S}_{z}$ crystals induced a much more rigid framework composed by $\left[\mathrm{GeS}_{4}\right]$ tetrahedral units in the residual glassy matrix. It would be a partial reason for the decreasing TECs with the separation of $\mathrm{Li}^{+}$and $\left[\mathrm{S}_{3} \mathrm{Ga}-\mathrm{GaS}_{3}\right]$ structural units. And the rebound for $80 \mathrm{~h}$ heat-treated sample can be attributed to the precipitation of main glass former ([GeS 4$]$ structrual units), which strongly destroys the rigid of residual glass network. Similarly, the mechanical properties of glass-ceramics are strongly influenced by the strong interatomic bonds that prevail. As a result, the enhanced hardness is also due to the compact reticulation in GGL-10 glassceramics. A point worth emphasizing is that due to the homogeneous generation of nano-crystals, the propagation of cracks is greatly inhibited in the crystallized glasses.

In this case of nanocrystalline glass-ceramics with enhanced mechanical properties, valuable SHG was observed using the Maker fringe method. The SHG in these glass-ceramics is ascribed to the SON effect of $\mathrm{Li}_{x} \mathrm{Ga}_{y} \mathrm{~S}_{z}$ crystallites with a $\mathrm{Ga}_{2} \mathrm{~S}_{3}$-like structure. It can be known that the precipitated $\mathrm{Li}_{x} \mathrm{Ga}_{y} \mathrm{~S}_{z}$ crystal belongs to the hexagonal system without a symmetrical center, which makes contributions to the SON effects. Additionally, based on the results obtained by Kityk, ${ }^{7}$ besides the $\mathrm{Li}_{x} \mathrm{Ga}_{y} \mathrm{~S}_{z}$ crystallites, the contribution of optically induced electron-photon interactions with nano-interfaces is another possible factor to enhance the hyperpolarizabilities. However, under the present experimental condition, due to the absence of an external IR optical poling and the extremely low power density of the fundamental wavelength $(\sim 3.0 \times$ $\left.10^{-4} \mathrm{GW} \mathrm{cm}{ }^{-2}\right),{ }^{6}$ it can be deduced that the IR-induced SHG do less contribution to the enhancement of SHG. Consequently in this case, the SHG in these glass-ceramics should be ascribed to the SON optical effect of $\mathrm{Li}_{x} \mathrm{Ga}_{y} \mathrm{~S}_{z}$ crystallites, which originates from the cationic-anion charge transfer determining the hyperpolarizability. Our previous investigation has shown that surface crystallization of glass-ceramics would lead to a broad fringe pattern of SHG, while the lobe profile is attributed to the resultant $\mathrm{SH}$ signals from both the surface crystalline layer and inner crystallites in the glassy matrix. ${ }^{6}$ Thus, the lobe profiles in Fig. 10(a) should be due to the volume-crystallization of glasses in this study. The decrease of the $\mathrm{SH}$ signal when the absolute incident angle of laser beam increases is mostly due to Fresnel losses at the interfaces at high angles. In this study, due to apparatus limitation, the wavelength of $\mathrm{SH}$ signal locates at the range of very low transmittance for the well-crystallized glasses, which is responsible for the relatively low intensity and large noise of SH profile. Taking account into the transmission loss, the $\mathrm{SH}$ intensity ratio of crystallized glass to $\mathrm{Y}$-cut $\alpha$-quartz reference at the application window $(2-12 \mu \mathrm{m})$ where has a maximum transmittance, should be much larger than that at $532 \mathrm{~nm}^{26}$ According to Powder technique described by Kurtz and Perry, ${ }^{27}$ the SHG intensity in a polycrystalline powder can be analyzed with regard to the $r / l_{\mathrm{c}}$ ratio where $r$ is the particle size and $l_{\mathrm{c}}$ is the coherent length of the particle, $l_{\mathrm{c}}=\lambda /\left[4\left(n_{2 \omega}-n_{\omega}\right)\right]$. For the nanocrystalline glass-ceramics, the value of $r / l_{\mathrm{c}}$ ratio is too low to get a phase match. Thus, the large SON effect in the obtained glass-ceramics is presumably resulted from the phase randomization due to the random distribution of the crystallite domains, similarly to the situation of quasi-phase-matching in the polycrystalline materials. ${ }^{24}$

On the other hand, despite that some studies have been focused on the $\mathrm{Li}^{+}$ionic conductivity of chalcogenide glasses, ${ }^{15,28}$ there is very little work on the ionic conductivity of the sulfide glass-ceramics. To the best of our knowledge, it should be the first effort to describe the mechanisms of ionic conduction in such composite materials. As indicated by the above results, at the initial crystallization process, the $\mathrm{Ga}_{2} \mathrm{~S}_{3}$-like crystals containing $\mathrm{Li}$ atoms is crystallized with the elongation of annealing times. Combined with the previous studies in glass-ceramics containing $\mathrm{Li}^{16,29}$ it can be concluded that the partial crystallization of crystalline phase $\left(\mathrm{Li}_{x} \mathrm{Ga}_{y} \mathrm{~S}_{z}\right)$ is responsible for the enhancement of ionic conductivity. Thus, we can see that the glass crystallized for $40 \mathrm{~h}$ has a higher conductivity than the base glass. This effect is possibly attributed to the fast ionic conduction at the interfaces between crystallites and the glassy phase. ${ }^{29}$ And then, with a much longer heat-treatment of $80 \mathrm{~h}$, the resultant ionic conductivity strongly decreases as shown in Fig. 11. The structural evidences for this change can be found as follows. The precipitation of $\mathrm{Li}_{x} \mathrm{Ga}_{y} \mathrm{~S}_{z}$ crystals where $\mathrm{Li}$ joins is finished after the $60 \mathrm{~h}$ heattreatment, and then this metastable crystal phase loses $\mathrm{Li}$ atoms with further heat treatments (as shown in Fig. 7), becoming a poorly conducting crystal with lower amount of Li. In the meantime, the poorly conducting crystallite grows and increases incessantly, leading to glass-ceramics with a large crystallinity degree. Therefore, all the facts suggest that the sharp drop of $\mathrm{Li}^{+}$ionic conductivity is caused by a blocking of the $\mathrm{Li}^{+}$motion by the poorly conducting crystallites. This study would be of reference value for the further research of chalcogenide glass-ceramics with a higher ionic conductivity, leading to the practical value of amorphous solid electrolytes.

\section{Conclusions}

Controllable nucleation and crystal growth were realized according to the calorimetry study in the GGL-10 glass. It 
has been manifested that the precipitation of $\mathrm{Li}_{x} \mathrm{Ga}_{y} \mathrm{~S}_{z}$ crystallites with $\mathrm{Ga}_{2} \mathrm{~S}_{3}$-like structure, which is responsible for the first $\mathrm{CP}$ on the DSC curve, terminated after $60 \mathrm{~h}$ heat-treatment at $403{ }^{\circ} \mathrm{C}$. And this heat-treated temperature has proved to be located at the overlap of nucleation and crystal-growth rate curves, indicating a controllable crystallization process. So then, the desired microstructure of nanocrystalline $\mathrm{Li}_{x} \mathrm{Ga}_{y} \mathrm{~S}_{z}$ crystallized glass is easily realized for enhanced thermomechanical properties, permanent SHG, and improved ionic conductivity.

The obtained glass-ceramics possess improved thermomechanical properties such as $\sim 8 \%$ enhancement for the hardness, $45 \%$ increase for fracture toughness, and $22 \%$ decrease for TEC, and meanwhile remain the advantage of good IR-transparency, even for the sample of $\sim 60 \%$ crystallinity degree. They may be partially originated from the fact that the transformation of glassy modifier $\mathrm{Li}^{+}$and $\left[\mathrm{S}_{3} \mathrm{Ga}-\mathrm{GaS}_{3}\right]$ structural units to $\mathrm{Li}_{x} \mathrm{Ga}_{y} \mathrm{~S}_{z}$ crystals induced a much more rigid and compact framework composed of [ $\left.\mathrm{GeS}_{4}\right]$ tetrahedral units in the residual glassy matrix. The wellcrystallized sample presents clear SHG phenomena and still keeps its transmittance in the application windows of 2-10 $\mu \mathrm{m}$ wavelength region, which was due to the precipitation of $\mathrm{Li}_{x} \mathrm{Ga}_{y} \mathrm{~S}_{z}$ crystal with $\mathrm{Ga}_{2} \mathrm{~S}_{3}$-like structure. In addition, it is found that $\mathrm{Li}^{+}$ionic conductivity of the obtained glassceramics increases firstly, and then decreases after a long heat-treatment. Based on the thermal and microstructural investigations, it is evidenced that the partial crystallization of superionic crystalline phase $\left(\mathrm{Li}_{x} \mathrm{Ga}_{y} \mathrm{~S}_{z}\right)$ is responsible for the enhancement of $\mathrm{Li}^{+}$ionic conductivity, and then the sharp drop is due to the blocking of the $\mathrm{Li}^{+}$motion by the poorly conducting crystallites with less $\mathrm{Li}$ atoms. Therefore, these IR-transparent glass-ceramics based on uniformly dispersed $\mathrm{Li}_{x} \mathrm{Ga}_{y} \mathrm{~S}_{z}$ crystals $<100 \mathrm{~nm}$ in size provide unique attributes such as a well enhanced resistance to environmental impairment, permanent SHG, and good ionic conductivity for current products and offer promise for many potential new applications.

\section{Acknowledgements}

This work was partially funded by Natural Science Foundation of China (NSFC) (60808024), the National Science Foundation (NSF) of Hubei Province, and the Program for Changjiang Scholars and Innovative Research Team (PCSIRT, No. IRT0547), Ministry of Education, China.

\section{References}

1 J. S. Sanghera and I. D. Aggarwal, J. Non-Cryst. Solids, 1999, 256-257, 6-16; A. Zakery and S. R. Elliott, J. Non-Cryst. Solids, 2003, 330, 1-12.

2 J. Ebothe, W. Imiolek, K. J. Plucinski and D. Hui, J. Mater. Sci.: Mater. Electron., 2008, 19, 233-236.

3 M. Guignard, V. Nazabal, F. Smektala, J. L. Adam, O. Bohnke, C. Duverger, A. Moréac, H. Zeghlache, A. Kudlinski, G. Martinelli and Y. Quiquempois, Adv. Funct. Mater., 2007, 17, 3284.
4 G. Dong, H. Tao, X. Xiao, C. Lin, X. Zhao and S. Mao, J. Phys. Chem. Solids, 2007, 68, 158-161.

5 H. Zeghlache, M. Guignard, A. Kudlinski, Y. Quiquempois, G. Martinelli, V. Nazabal and F. Smektala, J. Appl. Phys., 2007, 101, 084905.

6 C. Lin, H. Tao, X. Zheng, R. Pan, H. Zang and X. Zhao, Opt. Lett., 2009, 34, 437-439; C. Lin, H. Tao, R. Pan, X. Zheng, G. Dong, H. Zang and X. Zhao, Chem. Phys. Lett., 2008, 460, 125-128; Y. Takahashi, Y. Benino, T. Fujiwara and T. Komatsu, Appl. Phys. Lett., 2002, 81, 223-225.

7 I. V. Kityk, M. Guignard, V. Nazabal, X. H. Zhang, J. Troles, F. Smektala, B. Sahraoui and G. Boudebs, Phys. B, 2007, 391, 222-227; I. V. Kityk and B. Sahraoui, Phys. Rev. B: Condens. Matter Mater. Phys., 1999, 60, 942-949.

8 J. J. Mecholsky Jun, C. T. Moynihan, P. B. Macedo and G. R. Srinivasan, J. Mater. Sci., 1976, 11, 1952-1960.

9 H. Ma, L. Calvez, B. Bureau, M. L. Floch, X. Zhang and J. Lucas, J. Phys. Chem. Solids, 2007, 68, 968-971; L. Calvez, H. Ma, J. Lucas, P. Glouannec and X. Zhang, J. Non-Cryst. Solids, 2007, 353, 4702-4706; M. Guignard, V. Nazabal, X. Zhang, F. Smektala, A. Moréac, S. Pechev, H. Zeghlache, A. Kudlinski, G. Martinelli and Y. Quiquempois, Opt. Mater., 2007, 30, 338-345.

10 C. Lin, L. Calvez, M. Rozé, H. Tao, X. Zhang and X. Zhao, Appl. Phys. A: Mater. Sci. Process., 2009, 97, 713-720.

11 Z. G. Ivanova, E. Cernoskova and Z. Cernosek, J. Phys. Chem. Solids, 2007, 68, 1260-1262; Z. G. Ivanova, Z. Aneva, Z. Cernosek, E. Cernoskova and V. S. Vassilev, J. Mater. Sci.: Mater. Electron., 2003, 14, 761-762.

12 L. Calvez, P. Lucas, M. Rozé, H. Ma, J. Lucas and X. Zhang, Appl. Phys. A-Mater., 2007, 89, 183-188.

13 M. Rozé, L. Calvez, Y. Ledemi, M. Allix, G. Matzen and X. Zhang, J. Am. Ceram. Soc., 2008, 91, 3566-3570; L. Calvez, H. Ma, J. Lucas and X. Zhang, Adv. Mater., 2007, 19, 129-132.

14 D. N. Nikogosyan, in Nonlinear Optical Crystals: A Complete Survey, Springer, New York, USA, 2005, ch. 6, p. 269.

15 M. Yamashita and H. Yamanaka, Solid State Ionics, 2003, 158 151-156; J. Saienga and S. W. Martin, J. Non-Cryst. Solids, 2008, 354, 1475-1486.

16 F. Qi, C. Rier, R. Böhmer, W. Franke and P. Heitjans, Phys. Rev. B: Condens. Matter Mater. Phys., 2005, 72, 104301.

17 B. Roling, A. Schirmeisen, H. Bracht, A. Taskiran, H. Fuchs, S. Murugavel and F. Natrup, Phys. Chem. Chem. Phys., 2005, 7, $1472-1475$.

18 B. Bureau, J. Troles, M. L. Floch, P. Guénot, F. Smektala and J. Lucas, J. Non-Cryst. Solids, 2003, 319, 145-153.

19 D. Massiot, F. Fayon, M. Capron, I. King, S. L. Calvé, B. Alonso, J. O. Durand, B. Bujoli, Z. Gan and G. Hoatson, Magn. Reson. Chem., 2002, 40, 70-76.

20 J. P. Guin, T. Rouxel, J. C. Sanglebœuf, I. Melscoët and J. Lucas, J. Am. Ceram. Soc., 2002, 85, 1545-1552.

21 F. Xia, X. Zhang, J. Ren, G. Chen, H. Ma and J. L. Adam, J. Am. Ceram. Soc., 2006, 89, 2154-2157.

22 C. S. Ray, X. Fang and D. E. Day, J. Am. Ceram. Soc., 2000, 83, 865-872.

23 Y. Ledemi, L. Calvez, M. Rozé, X. Zhang, B. Bureau, M. Poulain and Y. Messaddeq, J. Optoelectron. Adv. M., 2007, 9, 3751-2755.

24 M. Baudrier-Raybaut, Ph. Hadar, R. Kupecek, Ph. Lemasson and E. Rosencher, Nature, 2004, 432, 374-376.

25 L. Calvez, PhD Thesis, University of Rennes 1, France, 2006.

26 H. A. Lu, L. A. Wills, B. W. Wessels, W. P. Lin, T. G. Zhang, G. K. Wong, D. A. Neumayer and T. J. Marks, Appl. Phys. Lett., 1993, 62, 1314.

27 S. K. Kurtz and T. T. Perry, J. Appl. Phys., 1968, 39, 3798.

28 J. Saienga, Y. Kim, B. Campbell and S. W. Martin, Solid State Ionics, 2005, 176, 1229-1236; W. Yao and S. W. Martin, Solid State Ionics, 2008, 178, 1777-1784.

29 A. Schirmeisen, A. Taskiran, H. Fuchs, H. Bracht, S. Murugavel and B. Roling, Phys. Rev. Lett., 2007, 98, 225901. 